\title{
Malignant fibrous histiocytoma of the conjunctiva ${ }^{\star}$
}

\author{
Jacob Pe'er, Shmuel Levinger, Michael Ilsar, Harold Climenhaga, Elimelech Okon
}

\begin{abstract}
Malignant fibrous histiocytoma (MFH) of the conjunctiva is an extremely rare tumour, and only three previous cases have been reported. We describe two patients with MFH of the conjunctiva: a 58-year-old white male with epibulbar tumour who had exenteration and is alive after five years' follow-up, and a 31/2-yearold African girl with xeroderma pigmentosum and an MFH of her right eye conjunctiva, the first reported case of this association. The characteristics and the methods of diagnosis of MFH are discussed.
\end{abstract}

Fibrous histiocytoma (FH) of the conjunctiva is a rare benign tumour, and only 10 such previous cases have been described. ${ }^{1-8}$ Two cases of conjunctival $\mathrm{FH}^{910}$ showed a benign histological appearance but a malignant clinical course. Malignant fibrous histiocytoma (MFH) of the conjunctiva is extremely rare, and only three cases have been reported. ${ }^{11-13}$ Five cases of FH were located in the eyelids. ${ }^{14-17}$ Orbital cases of $\mathrm{FH}$ are considered to be the commonest primary mesenchymal orbital tumour of adults. ${ }^{18}$. We report here two cases of malignant fibrous histiocytoma of the conjunctiva.

\section{Case reports}

\section{CASE I}

Clinical history. A 58-year-old man presented in

Hadassah University Hospital, Jerusalem, Israel

Department of

Ophthalmology

J Pe'er

S Levinger

M Ilsar

Department of Pathology E Okon

St John Ophthalmic Hospital, Jerusalem H Climenhaga

Correspondence to: Dr J Pe'er, Department of Ophthalmology, Hadassah University Hospital, PO Box 12000,91120 Jerusalem, Israel.

Accepted for publication 11 May 1990

^Presented at the 11th Biannual Meeting Washington, DC, June 1985 and the 13th Biannual Meetin of the AOA-AFIP

Washington, DC, June 1989. ing the initial pathology report of $\mathrm{MFH}$ the patient was called back for re-examination. There were no systemic signs or symptoms except for an enlarged right submandibular lymph node, which was removed. It showed reactive hyperplasia and no malignant tumour. One and a half months later the patient was found to have a recurrent epibulbar mass in the same quadrant, similar in size to the original tumour but several millimeters further back from the limbus (Fig 1). This was extensively resected the following day, and the same findings of malignancy were seen. Because of the known nature of this tumour, and in consultation with the Oncology Department, we decided to exenterate the right orbit. In five years of follow up there has been no evidence of recurrence or metastases.

Pathological findings. The specimen from the first excision consisted of a few pieces of partially pigmented soft tissue, the larger piece measuring $13 \times 9 \times 8 \mathrm{~mm}$. The specimen from the second excision consisted of two pieces of soft tissue, the larger measuring $7 \times 5.5 \times 3 \mathrm{~mm}$ and coated by some pigment. In cut section the tissue was homogeneously white.

Microscopic examination of both excisional biopsies revealed malignant cells showing striking pleomorphism and many mitotic figures (Fig 2). There were small round cells as well as very large cells and multinucleated giant cells. Most of their nuclei had one or more nucleoli. Many foamy cells with granular nuclei were seen (Fig 3). A fascicular pattern was observed in areas of the tumour. Immunohistochemical studies with the peroxidase-antiperoxidase technique (PAP) staining showed positive staining of many tumour cells for lysosome and vimentin

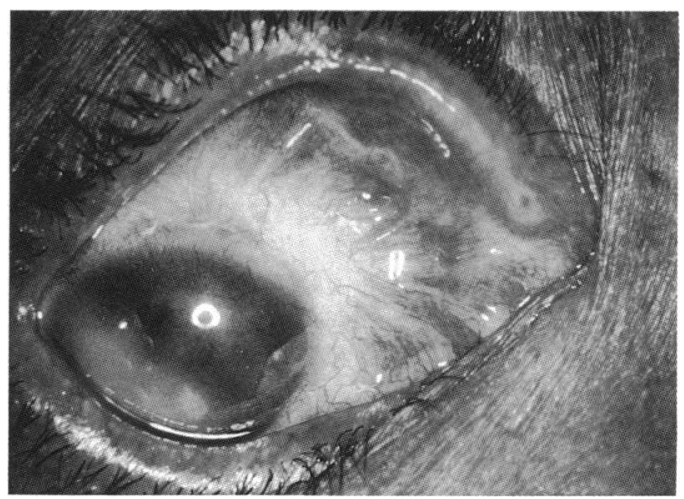

Figure 1 The right eye of case 1 presenting a recurrent epibulbar mass in the superonasal quadrant. 


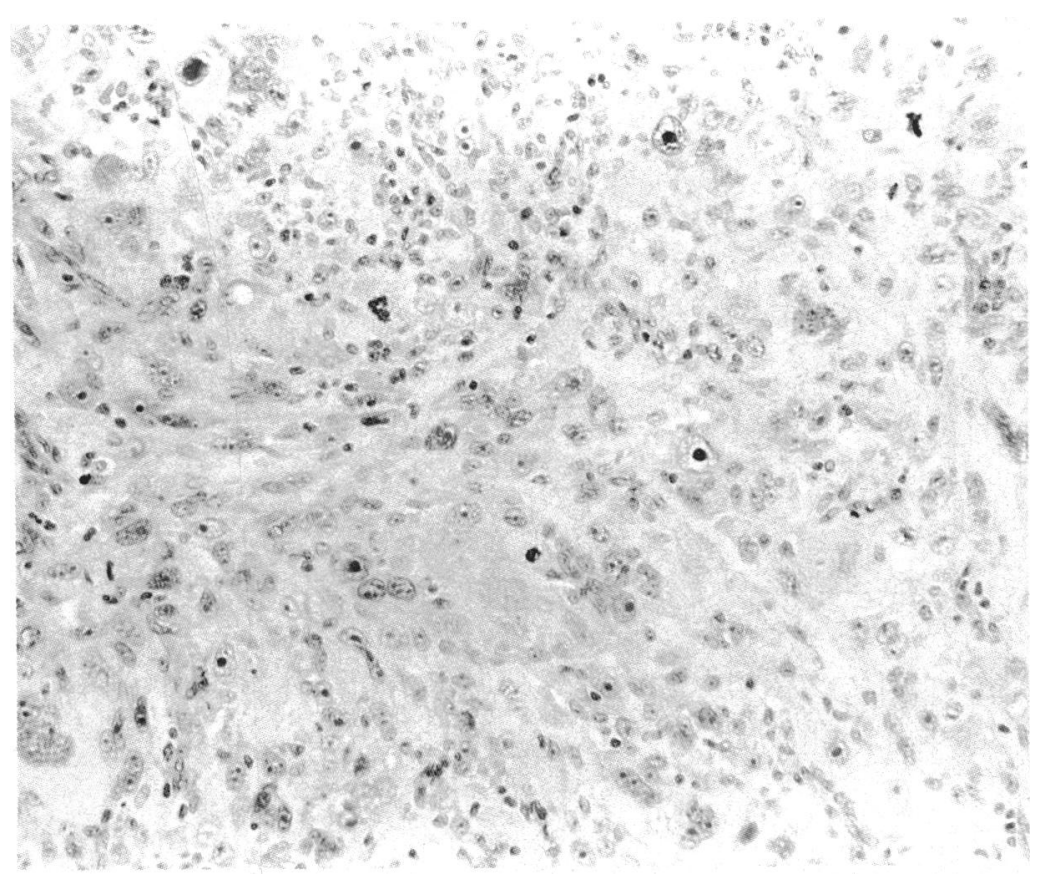

Figure 2 Case 1 shows a malignant pleomorphic soft tissue tumour with many mitotic figures and large giant cells (in left lower corner). (Haematoxylin and eosin, $\times 183$.)

Figure 3 Case 1 shows many pleomorphic malignant giant cells with hyperchromatic nuclei and prominent nucleoli. The cytoplasm of the large cell in the centre shows foamy cytoplasm. (Haematoxylin and eosin, $\times 730$.

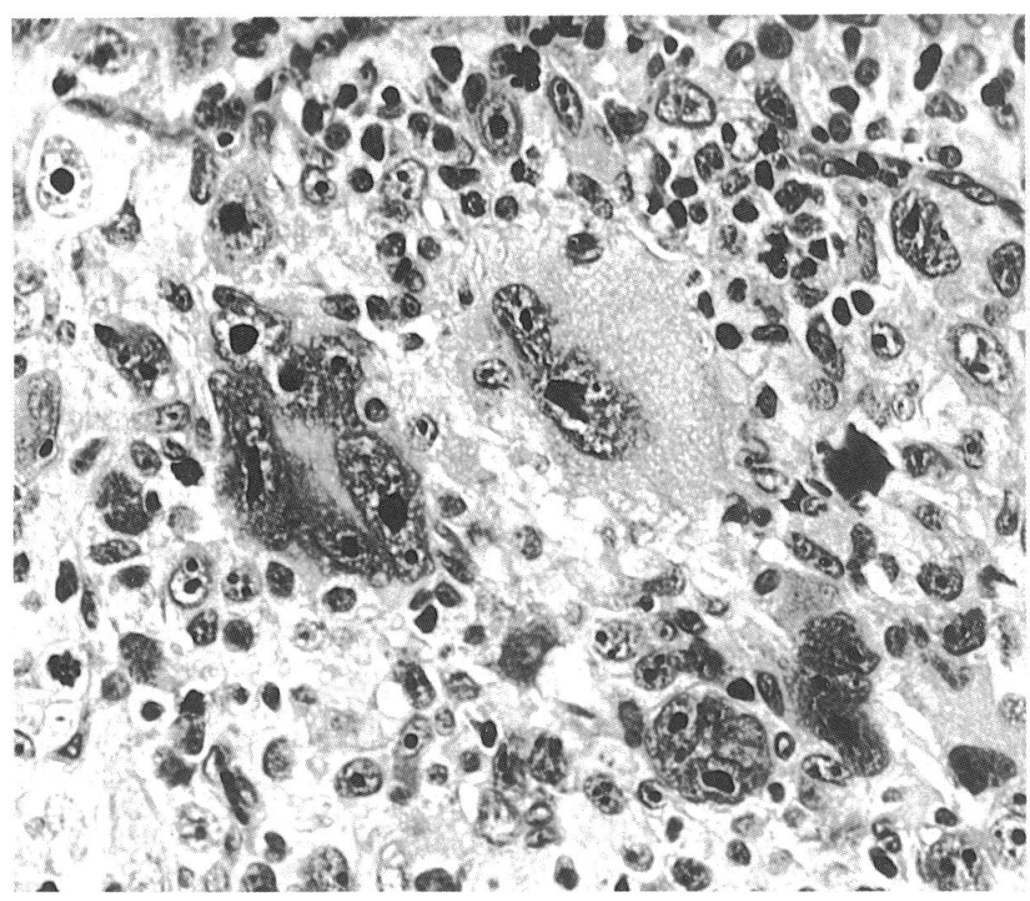

and negative staining for $\mathrm{S}-100$ protein and cytokeratin. The diagnosis was made of $\mathrm{MFH}$, pleomorphic type.

The exenteration specimen measured $38 \times 39 \times 39 \mathrm{~mm}$, and included the right eyeball, orbital contents, and eyelids. The optic nerve, $4 \mathrm{~mm}$ in length, was attached. There was a symblepharon of the upper fornix of the conjunctiva which was occupied by a whitish shallow mass. The cornea was partially opaque. The specimen was dissected vertically.

Microscopic examination of the exenteration specimen showed a section through the medial part of an eye globe and its adnexa. There were no remarkable finding in the eye. The conjunctiva showed chronic inflammatory infiltration. The conjunctival and eyelid tissue superior to the upper conjunctival fornix was massively infil- trated by chronic inflammatory cells and bizarre pleomorphic tumour cells, many of them with foamy cytoplasm. Some of them were multinucleated giant cells, identical to the cells found in the previous excisional biopsies. The borders of the exenteration specimen were free of tumour

Formalin-fixed tumour tissue was processed for electron microscopy. The tissues were fixed in $2 \%$ glutaraldehyde buffered in phosphatesaline buffer $(0 \cdot 1 \mathrm{M} ; \mathrm{pH} 7 \cdot 2)$ and postfixed in $1 \%$ $\mathrm{OsO}_{4}$ for one hour. After dehydration in graded ethanol the specimens were embedded in Spurr resin. Ultrathin sections of approximately $70 \mathrm{~nm}$ were collected on 300 mesh copper grids and contrasted with uranyl and lead citrate. The sections were examined with a Philips EM300 operating at $60 \mathrm{kV}$.

The electron microscopic studies showed in both types of cells the histiocytic as well as the fibroblasic variants, lipid cisternae as well as lysosomes. Dilated cisternae of rough-surfaced endoplasmic reticulum containing electrondense granular material were also found (Fig 4). In some areas broken parts of rough-surfaced endoplasmic reticulum were seen.

\section{CASE 2}

A 31/2-year-old girl presented to the Eye Clinic at Kamuzo Central Hospital in Lilongwe, Malawi, in February 1988 with tumours in both eyes. The mother was over 40 years old and the father was not known. One sister and two brothers were healthy. The child's birth had been normal, but her development had been slow. A few months after her birth the mother noticed 'changes' and, later, tumours on the child's exposed skin. There were no similar findings in other known family members. The girl was diagnosed as suffering from xeroderma pigmentosum.

Examination of the girl revealed microcephaly and mental retardation. The girl walked but did not speak. The skin of the face, including the eyelids, showed atrophic changes, pigmentation, depigmentated areas, and multiple tumours (Fig 5). Similar tumours were seen to a less extent on the neck, hands, and feet.

Examination of the left eye revealed a tumour of the bulbar conjunctiva. The cornea was not involved in the tumour but was hazy and partially vascularised. The right eye showed a large tumour of the bulbar conjunctiva with involvement of the cornea (Fig 5). A skin tumour was also noted on the upper lid. The intraocular structures could not be checked, and it was impossible to assess her visual acuity.

The tumours of the eyes were removed, and those of the skin were shaved. All specimens were sent to our laboratory for histopathological evaluation. The child was lost to follow-up.

The conjunctival corneal tumour of the right eye consisted of a brown piece of tissue measuring $12 \times 10 \times 7 \mathrm{~mm}$.

Microscopic examination revealed a tumour with striking pleomorphism, with many abnormal mitotic figures and areas with fascicular pattern of the cells (Fig 6). There were many large bizarre cells and multinucleated giant cells (Fig 7). Many of the cells showed foamy cyto- 
Figure 4 Case 1 electron microscopic examination reveals dilated cisternae of rough-surfaced endoplasmic reticulum with electron-dense granular material.

(Haematoxylin and eosin, $\times 60000$.)

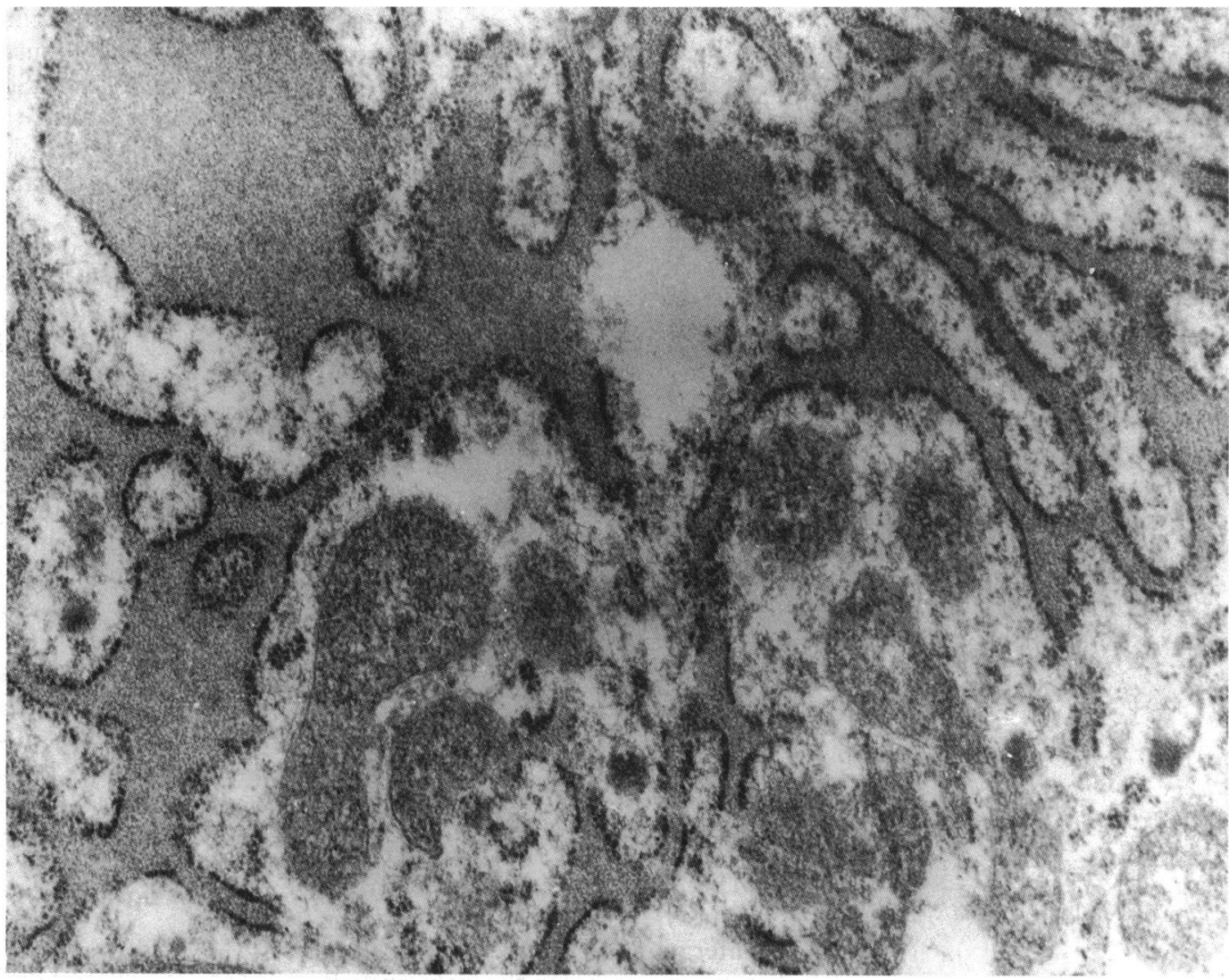

plasm. The tumour was infiltrated by inflammatory cells.

Immunohistochemical studies were positive for vimentin and lysozyme but negative for S-100 protein and cytokeratin.

\section{Discussion}

Malignant fibrous histiocytoma represents one of the commonest soft tissue tumours ${ }^{1920}$ and can occur in practically every part of the body. ${ }^{19-21}$ These tumours show a remarkable tendency to metastasise to regional lymph nodes in addition

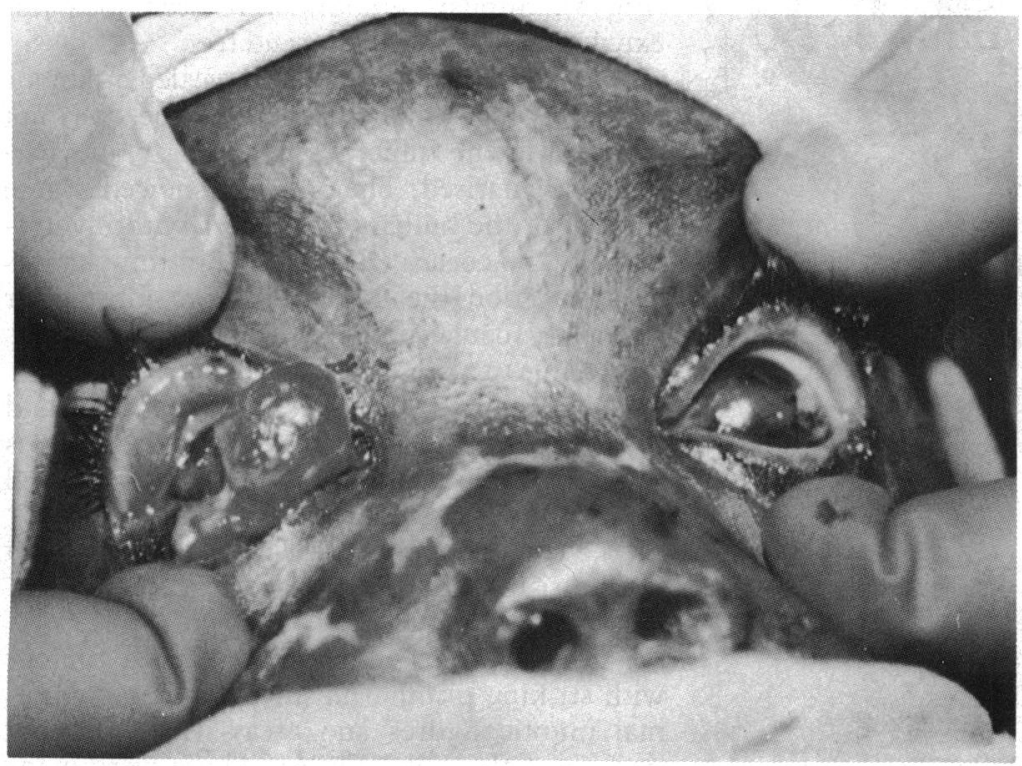

Figure 5 Case 2 shows atrophic changes of the skin of the face with pigmentation and depigmentation. The left eye has a small tumour of the bulbar conjunctiva and cormeal opacity. The right eye shows a large tumour of the bulbar conjunctiva with corneal involvement. to spreading by the blood stream. ${ }^{19-21}$ Their local aggressiveness is proved by their extremely high rate of local recurrence (100\% in one series) $)^{1920}$ when only limited excisions are performed. Therefore radical surgery is indicated in their treatment. ${ }^{20}$ Although $\mathrm{MFH}$ superficially situated in the subcutis is considered to have better prognosis than deeper tumours, there is no experience with MFH of the conjunctiva. These facts led us in case 1 to exenterate the whole orbital contents to the periosteum.

Other clinical features of our patient (case 1) are in accordance with those of most patients with $\mathrm{MFH}$ at other sites. ${ }^{18}$ The male sex is predominant, and the age distribution is from the third to the sixth decade. In addition the main histological features of $\mathrm{MFH}$ which were found in our case were comparable to those of MFH found elsewhere in the body. ${ }^{20}$

Case 2 is the first reported of xeroderma pigmentosum with MFH of either the skin or conjunctiva. Most of the neoplastic tumours in these cases are of epithelial origin, such as squamous cell carcinoma and basal cell carcinoma, or of melanocytic origin, such as malignant melanoma, which can be explained by the exposure of the skin cells to ultraviolet radiation. Soft tissue tumours in xeroderma pigmentosum are extremely rare, and only a few fibrosarcomas and angiomas of the skin have been described. ${ }^{22}$

Xeroderma pigmentosum occurs more commonly in whites, but in blacks the disease displays more severe ocular pathology and less severe skin involvement, ${ }^{22-24}$ probably because of the protective effect of the pigmented skin.

Ocular symptoms in xeroderma pigmentosum occur in up to $80 \%$ of the patients, and are 


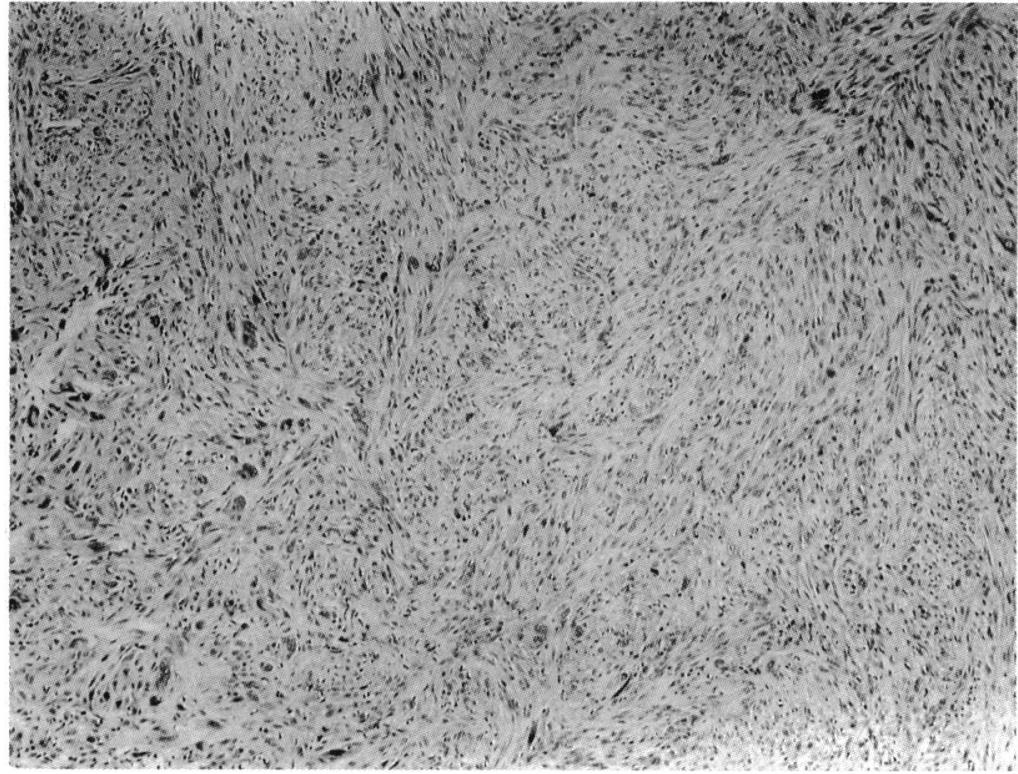

Figure 6 Case 2 shows a tumour with fascicles of spindled cells arranged in a storiform pattern. (Haematoxylin and eosin, $\times 73$.)

confined to the eyelids and anterior segment of the globe. ${ }^{25}$ Photophobia may start as early as age 2 years. The eyelids, especially the lower, may show atrophy of the skin, progressive madarosis, scarring, entropion, ectropion, trichiasis, lagophthalmos, symblepharon, ankyloblepharon, and sometimes loss of the entire lower lid substance. Basal cell carcinoma occurs frequently. Conjunctival findings may include hyperaemia, xerosis, oedema, mucoid exudates, keratinisation, hyperpigmentation, atrophy, pinguecula, and pseudopterygial changes and frank malignancies. The limbus is preferentially involved, especially in the interpalpebral zone. The cornea is frequently affected by vascularisation, opacification, and recurrent ulceration. Corneal or conjunctival-corneal neoplasms may occur. Inflammation of the iris may result in atrophy, abnormal pigmentation, and synechiae.

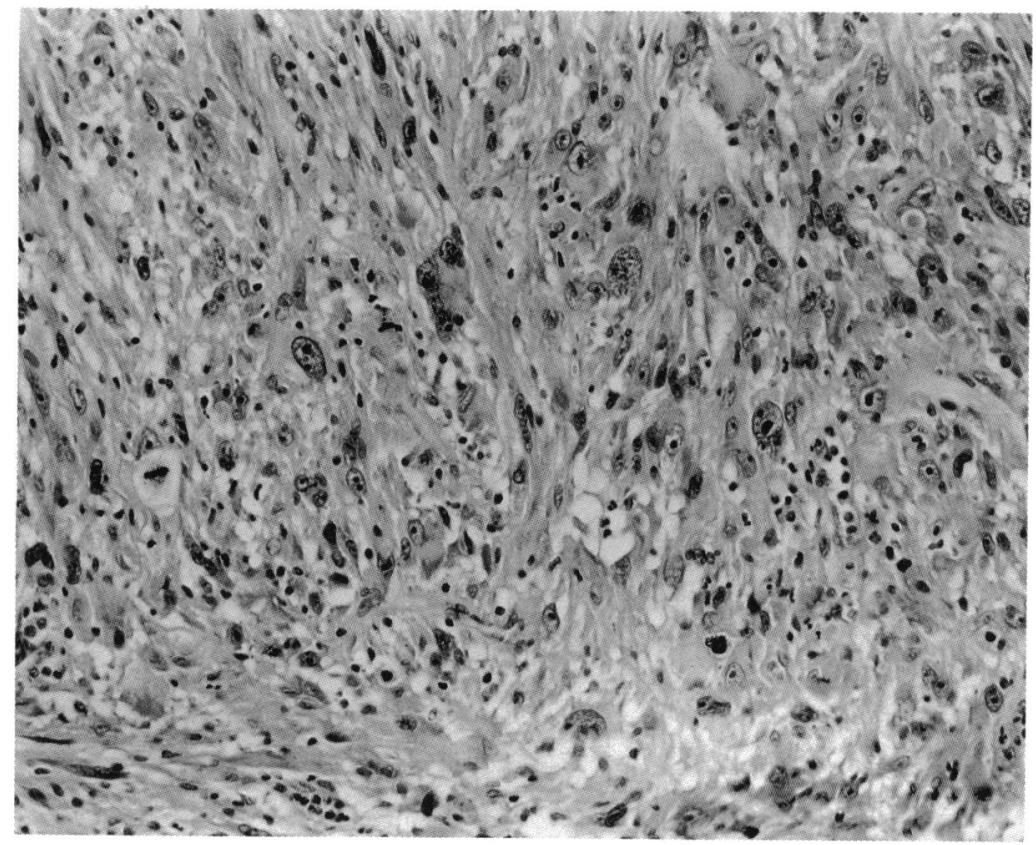

Figure 7 Case 2 shows large pleomorphic tumour cells with many mitotic figures and giant cells. Inflammatory cells are also seen. (Haematoxylin and eosin, $\times 183$.)
No characteristic alterations of the lens or fundus are seen.

In the largest survey of xeroderma pigmentosum, ocular neoplasms, apart from neoplasms of eyelids, were found in $11 \%$ of the patients. Neoplasms occurred most frequently at the limbus, followed by the cornea and conjunctiva. The most frequent histological type reported was squamous cell carcinoma, followed by basal cell carcinoma. There have been reports of five patients with ocular melanoma, including one with uveal tract melanoma. ${ }^{6}{ }^{26}$

Originally thought to arise from histiocytes and 'facultative' fibroblasts, MFH is now accepted as originating from a primitive mesenchymal cell with a capacity to differentiate along either or both cell lines. ${ }^{2011}$ Immunohistochemical studies ${ }^{27}$ and an ultrastructural analy$\mathrm{sis}^{28}$ of these tumours have raised questions about their histiocytic nature, and this subject is controversial. While one immunohistological study ${ }^{29}$ suggests that proliferating cells in MFH are of a histiocytic nature, other studies ${ }^{30-32}$ have raised the possibility that they are primarily fibroblastic in nature.

The markedly pleomorphic, highly malignant histological appearance of the tumours has caused us, as well as our consultants, difficulties in diagnosis. We considered in our differential diagnosis malignant melanoma with an unusual degree of cellular pleomorphism, as well as a bizarre kind of carcinoma. Immunohistochemical studies that were positive for lysosome and vimentin and negative for S- 100 protein and cytokeratin helped us to rule out the possibility of malignant melanoma or carcinoma and led us to the final diagnosis.

The electron microscopic findings of lipid vacuoles, lysozymes, and broken, rough endoplasmic reticulum were described and discussed in a previous report of benign $\mathrm{FH}$ of the conjunctiva. ${ }^{6}$ Our findings of a very dilated, rough surfaced, endoplasmic reticulum, which contained granular material, were described in two cases of $\mathrm{MFH}$ of the orbit. ${ }^{18}$ The role of electron microscopic studies in MFH has been discussed,,$^{20}$ and the authors concluded that there are no ultrastructural features which are specific for MFH: cells with similar characteristics can be found in other soft tissue tumours. The electron microscopic study is only an ancillary or confirmatory procedure in the diagnosis of MFH.

1 Albert DM, Smith RS. Fibrous xanthomas of the conjunctiva Arch Ophthalmol 1968; 80: 874-9.

2 Jakobiec FA. Fibrous histiocytoma of the corneoscleral limbus. Am $\mathcal{F}$ Ophthalmol 1974; 78: 700-6.

3 Flaudi JE, Kenvon K, Green WR. Fibrous histocitoma of the corneoscleral limbus. Am $\mathcal{F}$ Ophthalmol 1975; 80: 619-2t. 4 Elsas FJ, Green WR. Epibulbar tumors in childhood. A $m$ F Ophthalmol 1975; 79: 1001-7.

Paglen PG, Karcher DS, McMahon RT. Fibrous histiocytom of the conjunctiva. Ann Ophthalmol 1980; 12: 522-5.

Iwamoto T, Jakobiec FA, Darrell RW. Fibrous histiocytom of the corneoscleral limbus. Ophthalmology 1981: 88 1260-8.

7 Lahoud S, Brownstein S, Laflamme MY. Fibrous histio cytoma of the corneoscleral limbus and conjunctiva. Am f Ophthalmol 1988; 106: 579-83.

8 Kantelip B, Nores JM, Boccard R, Souoedan M, Bacin F Un cas d'histiocytome fibreux de la conjonctive. Presse Med 1988; 17: 859-61

9 Litricin O. Fibrous histiocytoma of the corneosclera. Arch Ophthalmol 1983; 101: +26-8.

10 Lew HR, Sheppard CL. Variations in management of adnexa tumors. A ust NZ F Ophthalmol 1985; 13: 189-91.

11 Delgado-Partida P, Rodriguez-Trujillo F. Fibrosarcoma 
(malignant fibrosarcoma) involving conjunctiva and ciliary body. Am f Ophthalmol 1972; 74: 479-85.

12 Urdiales-Viedma M, Moreno-Prieto M, Martos-Padilla S Pleomorphic fibrous histiocytoma of the corneoscleral limbus. Am $\mathcal{O}$ Ophthalmol 1983; 95: 560-1.

13 Margo CE, Horton MB. Malignant fibrous histiocytoma of the conjunctiva with metastasis. Am F Ophthalmol 1989; 107: conjun $433-4$.

14 Doxanas MT, Green WR, Arentsen JJ, Elsas, FJ. Lid lesions of childhood: a histologic survey at the Wilmer Institute of childhood: a histologic survey at the Wilmer Institute 7-39.

15 Harashina T, Maruyama Y, Kitamura K. The trilobed flap. Plast Reconstr Surg 1977; 60: 623-4.

16 Jakobiec FA, DeVoe AG, Boyd J. Fibrous histiocytoma of the tarsus. Am f Ophthalmol 1977; 84: 794-7.

17 John T, Yanoff M, Scheie HG. Eyelid fibrous histiocytoma. Ophthalmology 1981; 88: 1193-5.

18 Font RL, Hidayat AA. Malignant fibrous histiocytoma of the orbit. A clinicopathologic study of 150 cases. Hum Patho 1982; 13: 195-209.

19 Laties R. Malignant fibrous histiocytoma. A review article. Am F Surg Pathol 1982; 6: 761-7.

20 Weiss SW. Malignant fibrous histiocytoma. A reaffirmation. Am $\mathcal{F}$ Surg Pathol 1982; 6: 773-84.

21 Lattes R, ed. Tumors of the soft tissues (atlas of tumor pathology series) AFIP; 1982: 130-46.

22 Kraemar K, Lee MM, Scotto J. Xeroderma pigmentosum. Cutaneous, ocular and neurologic abnormalities in 830 published cases. Arch Dermatol 1987; 123: 241-50.
23 Bellows RA, Lahav M, Lepreau FJ, Albert DM. Ocular manifestations of xeroderma pigmentosum in a black family. Arch Ophthalmol 1974; 92: 113-7.

24 Freedman J. Corneal transplantation with associated histopathologic description in xeroderma pigmentosum occur-

ring in a black family. Ann Ophthalmol 1979; 11: 445-50. Report of two cases. Ann Ophthalmol 1982;14:580-5.

26 Kitogawa $K$, Oishi $T$, Inoue $M$. Choroidal malignant melanoma occurring in a patient with xeroderma pig mentosum. F

27 du Boulay CEHA. Demonstration of antitrypsin and antichymotrypsin in fibrous histiocytomas using the immunoperoxidase technique. Am J Surg Pathol 1982; 6: 559-64.

8 Hoffman MA, Dickearsin GR. Malignant fibrous histiocytoma. An ultrastructural study of eleven cases. Hum Pathol 1983; 14: 913-22.

29 Inoue A, Aozasa $K$, Tsujmoto $M$, Tamai $M$, Chatani F, Ueno H. Immunohistological study of malignant fibrous histiocytoma. Acta Pathol fpn 1983; 34: 759-65.

30 Wood GS, Beckstead JH, Tuner RR, et al. Malignant fibrous histiocytoma tumor cells resemble fibroblasts. Am 7 Surg Pathol 1986; 10: 323-35.

31 Brecher ME, Wilbur HF. Absence of mononuclear phagocyte antigens in malignant fibrous histiocytoma. Am $\mathscr{f}$ Clin Pathol 1986; 86: 344-8.

32 Roholl PJM, Kleyne J, Van Unnite JAM. Characterization of tumor cells in malignant fibrous histiocytoma and other soft tissue tumors in comparison with malignant histiocytes. $A m$ f Pathol 1985; 121: 269-74. 